\title{
Preoperative Pulmonary Rehabilitation Versus Chest Physical Therapy in Patients Undergoing Lung Cancer Resection: A Pilot Randomized Controlled Trial
}

\author{
Maria T. Morano, PhD, ${ }^{\mathrm{a}, \mathrm{b}}$ Amanda S. Araújo, PT, ${ }^{\mathrm{b}}$ Francisco B. Nascimento, PT, \\ Guilherme F. da Silva, PT, ${ }^{b}$ Rafael Mesquita, PT, ${ }^{\mathrm{c}}$ Juliana S. Pinto, MSc, ${ }^{d}$ \\ Manoel 0. de Moraes Filho, PhD, ${ }^{a}$ Eanes D. Pereira, $\mathrm{PhD}^{\mathrm{a}, \mathrm{b}}$
}

From the ${ }^{a}$ Universidade Federal do Ceará (UFC), Fortaleza, Brazil; ${ }^{b}$ Hospital de Messejana Dr. Carlos Alberto Studart Gomes, Secretaria de Saúde do Estado do Ceará (SESA), Ceará, Brazil; 'Centro de Pesquisa em Ciências da Saúde (CPCS), Centro de Ciências Biológicas e da Saúde (CCBS), Universidade Norte do Paraná (UNOPAR), Londrina, Brazil; and 'Universidad de Salamanca (USAL), Salamanca, Spain.

\begin{abstract}
Objective: To evaluate the effect of 4 weeks of pulmonary rehabilitation (PR) versus chest physical therapy (CPT) on the preoperative functional capacity and postoperative respiratory morbidity of patients undergoing lung cancer resection.

Design: Randomized single-blinded study.

Setting: A teaching hospital.

Participants: Patients undergoing lung cancer resection $(\mathrm{N}=24)$.

Interventions: Patients were randomly assigned to receive PR (strength and endurance training) versus CPT (breathing exercises for lung expansion). Both groups received educational classes.

Main Outcome Measures: Functional parameters assessed before and after 4 weeks of PR or CPT (phase 1), and pulmonary complications assessed after lung cancer resection (phase 2).

Results: Twelve patients were randomly assigned to the PR arm and 12 to the CPT arm. Three patients in the CPT arm were not submitted to lung resection because of inoperable cancer. During phase 1 evaluation, most functional parameters in the PR group improved from baseline to 1 month: forced vital capacity (FVC) $(1.47 \mathrm{~L}[1.27-2.33 \mathrm{~L}]$ vs $1.71 \mathrm{~L}[1.65-2.80 \mathrm{~L}]$, respectively; $P=.02)$; percentage of predicted FVC (FVC\%; $62.5 \%[49 \%-71 \%]$ vs $76 \%$ [65\%-79.7\%], respectively; $P<.05) ; 6$-minute walk test $(425.5 \pm 85.3 \mathrm{~m}$ vs $475 \pm 86.5 \mathrm{~m}$, respectively; $P<.05)$; maximal inspiratory pressure $\left(90 \pm 45.9 \mathrm{cmH}_{2} \mathrm{O}\right.$ vs $117.5 \pm 36.5 \mathrm{cmH}_{2} \mathrm{O}$, respectively; $\left.P<.05\right)$; and maximal expiratory pressure $\left(79.7 \pm 17.1 \mathrm{cmH} \mathrm{H}_{2} \mathrm{O}\right.$ vs $92.9 \pm 21.4 \mathrm{cmH}_{2} \mathrm{O}$, respectively; $\left.P<.05\right)$. During phase 2 evaluation, the PR group had a lower incidence of postoperative respiratory morbidity $(P=.01)$, a shorter length of postoperative stay $(12.2 \pm 3.6 \mathrm{~d}$ vs $7.8 \pm 4.8 \mathrm{~d}$, respectively; $P=.04)$, and required a chest tube for fewer days $(7.4 \pm 2.6 \mathrm{~d}$ vs $4.5 \pm 2.9 \mathrm{~d}$, respectively; $P=.03)$ compared with the CPT arm.

Conclusions: These findings suggest that 4 weeks of PR before lung cancer resection improves preoperative functional capacity and decreases the postoperative respiratory morbidity.
\end{abstract}

Archives of Physical Medicine and Rehabilitation 2013;94:53-8

(C) 2013 by the American Congress of Rehabilitation Medicine

The most effective treatment for lung cancer remains complete surgical resection with curative intent. ${ }^{1}$ A previous study ${ }^{2}$ showed a survival rate of $51 \%$ at 3 years for patients with a potentially

No commercial party having a direct financial interest in the results of the research supporting this article has or will confer a benefit on the authors or on any organization with which the authors are associated.

Clinical Trial Registration No.: RBR-3nm5bv. curable lung cancer. Unfortunately, only $20 \%$ to $30 \%$ of individuals with lung cancer are found to be candidates for lung resection, owing to the stage of their disease, a limited functional capacity, or associated comorbidities. ${ }^{3,4}$

For patients who can undergo surgery, the risk of postoperative pulmonary complications (PPCs) is increased. ${ }^{3-5}$ Decreasing the risk of respiratory morbidity in the postoperative period will allow a safer recovery from surgery. Poor functional capacity is 
associated with higher rates of PPCs, making the assessment of functional capacity part of the decision-making process for the surgical treatment of lung cancer. ${ }^{5}$

Preoperative pulmonary rehabilitation (PR) has been demonstrated to significantly improve exercise capacity, dyspnea, and health-related quality of life in patients awaiting lung volume reduction surgery and lung transplantation. ${ }^{6,7}$ The scarcity of publications about PR before lung cancer resection is evident in the literature; there are few studies with the aim of optimizing preoperative lung function and global conditioning of the patients. ${ }^{7-13}$ Just 1 randomized study ${ }^{14}$ has been published to date showing the beneficial effect of a short-term preoperative PR program on the postoperative morbidity of patients with moderate to severe chronic obstructive pulmonary disease (COPD) undergoing lung cancer resection.

The aim of this study was to assess the impact of 4 weeks of PR versus chest physical therapy (CPT) on the preoperative functional capacity and postoperative respiratory morbidity of patients undergoing lung cancer resection. We hypothesized that the PR program would improve the preoperative functional capacity and decrease the postoperative respiratory morbidity.

\section{Methods}

This randomized single-blinded study was conducted at a teaching hospital in Ceará (northeastern Brazil). All subjects gave their informed written consent before participation, and the study was previously approved by the institutional review board.

Criteria for inclusion in the study were the following: patients had to have (1) non-small cell lung cancer resection by open thoracotomy or by video-assisted thoracoscopy; and (2) previous pulmonary disease, interstitial lung disease, or obstructive airway disease, with impaired respiratory function by spirometry.

This randomized study tested 4 weeks ( 5 sessions per week) of preoperative PR versus CPT.

The rehabilitation group used the following protocol. The upper limb incremental test was based on a principle called the proprioceptive neuromuscular facilitation method that uses muscle groups in diagonal movement patterns. The upper limb performs a diagonal movement (primitive diagonal) starting from the opposite iliac crest (rest position) going outwards and upwards until it reaches the maximum shoulder flexion, then it goes back to the initial rest position. The initial load is $500 \mathrm{~g}$, with an increase of $500 \mathrm{~g}$ each minute. Patients must perform a minimum rate of 15 repetitions per minute.

Lower extremity endurance training had a target time of 30 minutes and was performed on a treadmill. In the first week, the patients performed 10 minutes of walking on a treadmill. The duration was built up to 30 minutes during the first 3 weeks of the program, with increments of 10 minutes each week. In the last week they performed 30 minutes of walking. Exercise intensity

\begin{tabular}{|l|}
\hline List of abbreviations: \\
COPD chronic obstructive pulmonary disease \\
CPT chest physical therapy \\
IMT inspiratory muscle training \\
MEP maximal expiratory pressure \\
MIP maximal inspiratory pressure \\
PPC postoperative pulmonary complication \\
PR pulmonary rehabilitation \\
6MWT 6-minute walk test \\
\hline
\end{tabular}

was based on $80 \%$ of the maximum load achieved during a treadmill incremental test.

Inspiratory muscle training (IMT) was performed using the Threshold Inspiratory Muscle Trainer. ${ }^{\text {a }}$ Daily IMT sessions of 10 to 30 minutes' duration were performed. Patients started breathing at a resistance that required generation of $20 \%$ of their maximal inspiratory pressure (MIP) and kept this intensity during the first week. The load was then increased by $5 \%$ to $10 \%$ each session, to reach a generation of $60 \%$ of their MIP at the end of the first month.

Flexibility, stretching, and balance exercises were included as part of the warmup and cooldown section of each exercise session.

The protocol for the group receiving conventional CPT consisted of instructions about the techniques for lung expansion: sustained maximal inspiration, fractional inspiration with or without a pause for inspiration hold, breathing patterns (diaphragmatic), pursed lips, and flow-based incentive spirometry. ${ }^{b}$ This group did not perform IMT.

All the patients participated in classes about the importance of preoperative and postoperative care and knowledge of the surgical process, energy conservation techniques, relaxation and stress management techniques, focus on nutrition, and the need to seek health services when necessary. There was no control group for the minimum education and preoperative IMT.

Before randomization, the patients had a functional evaluation that consisted of the following measures: spirometry, MIP, maximal expiratory pressure (MEP), 6-minute walk test (6MWT), and blood gas measurements. If necessary, the drug treatment was optimized. After that, patients were randomly assigned to undergo a preoperative PR or CPT program. The randomization was done in "blocks" of 4, and individual allocations were placed in sealed envelopes. An external investigator blinded to the allocation sequence picked the envelopes.

A new functional evaluation was performed during the last daily session of the programs. The surgery was scheduled immediately after that last evaluation. The surgical techniques and the teams were not selected.

Endpoints of this study were evaluated in 2 phases:

- Phase 1: The functional parameters after the completion of the programs (spirometry, MEP, MIP, 6MWT, and blood gas measurements)

- Phase 2: Hospital length of stay and PPCs-pneumonia (new infiltrate plus either fever [temperature $>38^{\circ} \mathrm{C}$ ] and white blood cell count $>11,000$, or fever and purulent secretions), bronchopleural fistula, bronchospasm, severe atelectasis (confirmed by chest radiographs, requiring chest physiotherapy or bronchoscopy), prolonged need for chest tubes $(>7 \mathrm{~d})$, and prolonged mechanical ventilation $(>48 \mathrm{~h})$.

Postoperative outcomes were obtained from the medical records by a physical therapist blinded to the treatment assignment.

Data analysis was performed using the SPSS for Windows 16.0. ${ }^{\mathrm{c}}$ Data are expressed as mean $\pm \mathrm{SD}$. In all continuous variables, the distribution was assessed by means of the KolmogorovSmirnov test. Normally distributed variables were compared by paired $t$ test and the Wilcoxon rank-sum test whenever parametric tests were inappropriate.

Continuous variables were tested between the 2 treatment arms (PR vs CPT) using the Student $t$ test. Categorical variables were tested using Fisher exact tests. Nonnormal variables were assessed 


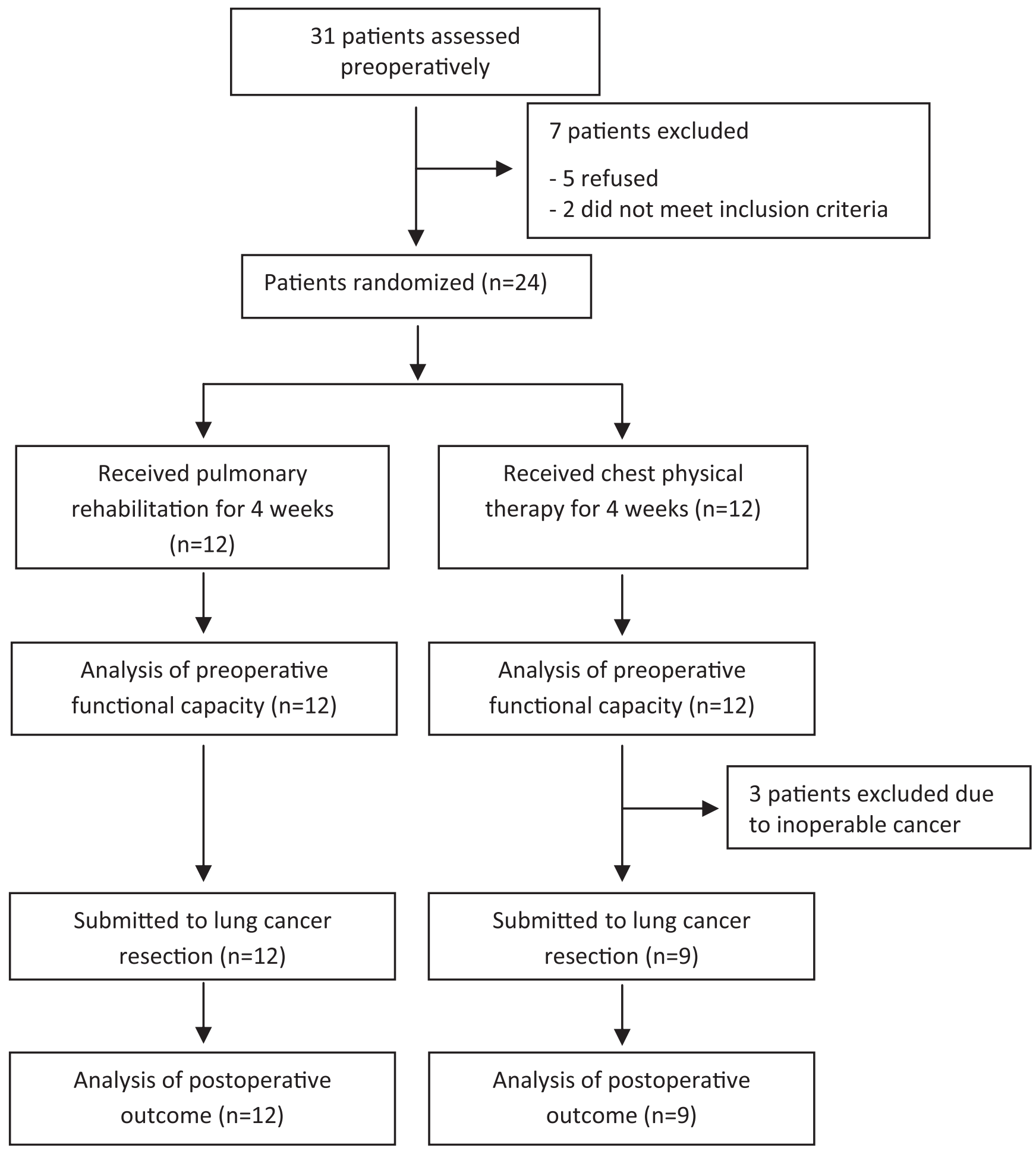

Fig 1 Flow diagram of the randomized controlled trial of 4 weeks of PR versus CPT before lung cancer resection.

by Mann-Whitney $U$ for 2 independent samples. All tests were 2-sided tests, and significance was set at $P<.05$.

\section{Results}

This randomized trial study recruited 31 patients between the period of March 2008 and March 2011 from a teaching hospital in Ceará (northeastern Brazil). After that, 7 patients were excluded, of whom 5 patients refused participation, and 2 patients did not meet inclusion criteria because of normal pulmonary function.

Twenty-four patients were randomly assigned, 12 to the PR arm and 12 to the CPT arm. All the patients from the PR group and the CPT group successfully completed the 5 sessions per week during 1 month. Three patients in the CPT arm were not submitted to lung resection because of inoperable cancer. The final analysis 
Table 1 Patients' characteristics and actual values of baseline functional parameters

\begin{tabular}{|c|c|c|c|c|c|c|c|}
\hline $\begin{array}{l}\text { Patients' } \\
\text { Group }\end{array}$ & $\begin{array}{l}\text { Age } \\
\text { (y) }\end{array}$ & Sex & $\begin{array}{l}\mathrm{FEV}_{1} \\
(\mathrm{~L}) \\
\end{array}$ & $\begin{array}{l}\text { FVC } \\
(\mathrm{L})\end{array}$ & $\begin{array}{l}\text { MIP } \\
\left(\mathrm{cmH}_{2} \mathrm{O}\right)\end{array}$ & $\begin{array}{l}\text { MEP } \\
\left(\mathrm{cmH}_{2} \mathrm{O}\right)\end{array}$ & $\begin{array}{l}\text { 6MWT } \\
(\mathrm{m}) \\
\end{array}$ \\
\hline PR & 59 & $\mathrm{~F}$ & 0.67 & 1.49 & 130 & 75 & 369 \\
\hline PR & 57 & $\mathrm{~F}$ & 0.72 & 1.08 & 50 & 70 & 382 \\
\hline PR & 59 & $M$ & 1.23 & 2.42 & 70 & 75 & 579 \\
\hline PR & 68 & $M$ & 0.92 & 1.20 & 100 & 115 & 535 \\
\hline PR & 62 & $F$ & 0.86 & 1.24 & 95 & 85 & 421 \\
\hline PR & 79 & $F$ & 0.58 & 1.46 & 70 & 90 & 354 \\
\hline PR & 54 & $\mathrm{~F}$ & 0.78 & 1.40 & 25 & 82 & 365 \\
\hline PR & 44 & $\mathrm{~F}$ & 1.50 & 1.88 & 150 & 75 & 527 \\
\hline PR & 76 & $\mathrm{~F}$ & 1.60 & 2.16 & 45 & 80 & 426 \\
\hline PR & 78 & $F$ & 0.77 & 1.38 & 150 & 50 & 300 \\
\hline PR & 73 & $M$ & 1.32 & 2.55 & 45 & 60 & 376 \\
\hline PR & 69 & $M$ & 1.60 & 2.39 & 150 & 100 & 473 \\
\hline CPT & 75 & $F$ & 1.35 & 2.27 & 40 & 40 & 390 \\
\hline CPT & 57 & $M$ & 1.23 & 2.20 & 100 & 100 & 482 \\
\hline CPT & 74 & $\mathrm{~F}$ & 1.26 & 2.25 & 60 & 35 & 300 \\
\hline CPT & 74 & $F$ & 0.77 & 1.44 & 50 & 30 & 250 \\
\hline CPT & 62 & $\mathrm{~F}$ & 1.32 & 1.87 & 25 & 85 & 396 \\
\hline CPT & 65 & $\mathrm{~F}$ & 0.93 & 1.61 & 25 & 40 & 420 \\
\hline CPT & 80 & $M$ & 1.03 & 1.68 & 25 & 60 & 173 \\
\hline CPT & 68 & $\mathrm{~F}$ & 1.63 & 3.00 & 70 & 50 & 430 \\
\hline CPT & 65 & $\mathrm{~F}$ & 1.10 & 1.15 & 25 & 35 & 216 \\
\hline CPT & 68 & $M$ & 0.67 & 1.49 & 40 & 34 & 376 \\
\hline CPT & 64 & $M$ & 1.23 & 2.42 & 25 & 80 & 254 \\
\hline CPT & 65 & $M$ & 1.63 & 3.00 & 70 & 46 & 392 \\
\hline
\end{tabular}

Abbreviations: $F$, female; $\mathrm{FEV}_{1}$, forced expiratory volume in the first second; FVC, forced vital capacity; M, male.
Table 2 Baseline characteristics of the 24 patients before 4 weeks of PR vs CPT

\begin{tabular}{|c|c|c|c|}
\hline Parameter & $\begin{array}{l}\text { CPT } \\
(n=12)\end{array}$ & $\begin{array}{l}P R \\
(n=12)\end{array}$ & $P$ \\
\hline Age $(y)^{*}$ & $68.8 \pm 7.3$ & $64.8 \pm 8$ & .33 \\
\hline Male $^{\dagger}$ & $5(41.6)$ & $4(33.3)$ & .46 \\
\hline Current smoker ${ }^{\dagger}$ & $9(75)$ & $10(83.3)$ & .44 \\
\hline Comorbidity $^{\dagger}$ & $4(33.3)$ & $7(58.3)$ & .35 \\
\hline \multicolumn{4}{|c|}{ Previous pulmonary disease ${ }^{\dagger}$} \\
\hline With COPD & $10(58)$ & $9(75)$ & .62 \\
\hline Without COPD & $2(16)$ & $3(25)$ & \\
\hline \multicolumn{4}{|c|}{ Lung cancer stage ${ }^{\dagger}$} \\
\hline Stage I/II & $9(75)$ & $11(91)$ & .16 \\
\hline Stage IIIA & $3(33)$ & $1(8.3)$ & \\
\hline $\operatorname{MIP}\left(\mathrm{cmH}_{2} \mathrm{O}\right)^{*}$ & $46 \pm 26.2$ & $90 \pm 45.9$ & .01 \\
\hline $\operatorname{MEP}\left(\mathrm{cmH}_{2} \mathrm{O}\right)^{*}$ & $52 \pm 24.5$ & $79 \pm 17.1$ & .02 \\
\hline $\mathrm{P}_{2}(\mathrm{mmHg})^{*}$ & $75.8 \pm 5.8$ & $79 \pm 8.8$ & .23 \\
\hline $\mathrm{PCO}_{2}(\mathrm{mmHg})^{*}$ & $41.8 \pm 3.8$ & $42.5 \pm 3.6$ & .39 \\
\hline Sat $\mathrm{O}_{2}(\%)^{*}$ & $94.7 \pm 1.2$ & $95.1 \pm 1.5$ & .88 \\
\hline $\mathrm{FEV}_{1}(\mathrm{~L})^{*}$ & $1.18 \pm .25$ & $1.07 \pm .37$ & .32 \\
\hline $\mathrm{FEV}_{1}(\%)^{*}$ & $49.1 \pm 11.9$ & $48.1 \pm 13.9$ & .41 \\
\hline $\mathrm{FVC}(\mathrm{L})^{\ddagger}$ & $2.03(1.52-2.38)$ & $1.47(1.27-2.33)$ & .32 \\
\hline FVC $(\%)^{\ddagger}$ & $62.5(49.5-71)$ & $62.5(56.2-92.5)$ & .26 \\
\hline $6 M W T(m) *$ & $339 \pm 107.9$ & $425 \pm 85.3$ & .06 \\
\hline
\end{tabular}

NOTE. Values are mean $\pm S D, n(\%)$, or median (25th-75th percentiles). Abbreviations: $\mathrm{FEV}_{1}$, forced expiratory volume in the first second; FVC, forced vital capacity; $\mathrm{PCO}_{2}$, carbon dioxide partial pressure; $\mathrm{P}_{2}$, oxygen partial pressure; Sat $\mathrm{O}_{2}$, peripheral oxygen saturation.

* Student $t$ test.

$\dagger$ Fisher exact test.

$¥$ Mann-Whitney $U$ test. of the postoperative outcome was based on data from 21 patients (12 from the CPT arm, 9 from the PR arm) (fig 1).

Of these 24 patients, 19 had a diagnosis of COPD, ${ }^{15} 2$ interstitial lung disease, and 3 bronchiectasis. Twenty patients had their resections by open thoracotomy and 1 patient by video-assisted thoracoscopy. Patients' characteristics and actual values of baseline functional parameters are presented in table 1 . The baseline characteristics observed between the 2 treatment arms (PR vs CPT) were comparable for demographic, clinical, surgical, and functional parameters except for the measures of MIP and MEP (table 2).

The improvement in functional parameters was evident from baseline to 1 month for the PR group. Significant increases were found for the following parameters: forced vital capacity both in liters $(1.68 \pm .57 \mathrm{~L}$ vs $2.11 \pm .69 \mathrm{~L}$, respectively; $P=.02)$ and percentage of that predicted $(59.6 \% \pm 15.1 \%$ vs $74.9 \% \pm 16.7 \%$, respectively; $P=.00), 6 \mathrm{MWT} \quad(425.5 \pm 85.3 \mathrm{~m}$ vs $475 \pm 86.5 \mathrm{~m}$, respectively; $P=.00)$, MIP $\left(90 \pm 45.9 \mathrm{cmH}_{2} \mathrm{O}\right.$ vs $117.5 \pm 36.5 \mathrm{cmH}_{2} \mathrm{O}$, respectively; $P=.00)$, and $\mathrm{MEP} \quad\left(79.7 \pm 17.1 \mathrm{cmH}_{2} \mathrm{O}\right.$ vs $92.9 \pm 21.4 \mathrm{cmH}_{2} \mathrm{O}$, respectively; $P=.00$ ). These improvements were not observed in the CPT group (table 3 ).

The main differences between patients in the PR versus CPT groups after surgery were the following: patients in the PR group had fewer days in the hospital $(7.8 \pm 4.8 \mathrm{~d}$ vs $12.2 \pm 3.6 \mathrm{~d} ; P=.04)$, fewer days needing a chest tube $(4.5 \pm 2.9 \mathrm{~d}$ vs $7.4 \pm 2.6 \mathrm{~d} ; P=.03)$, and a lower incidence of PPCs $(16.7 \%$ vs $77.8 \% ; P=.01)$ (table 4). An intention-to-treat analysis was done including the 3 patients in the CPT group who did not have surgery and assuming no change for the PPCs. Results analyzed both by intention to treat and per protocol showed that the CPT group had more postoperative complications than the PR group.

\section{Discussion}

In this exploratory randomized trial, participation in a 4-week PR program before lung cancer resection was associated with improvements in preoperative functional capacity, fewer PPCs, and a shorter length of postoperative hospital stay.

The studies about the benefits of PR in patients with cancer, particularly in the perioperative setting for lung cancer, are scarce in the literature. ${ }^{4-6,16}$ Cesario et al $^{13}$ have reported the beneficial effect of a 4-week inpatient preoperative PR program in 8 patients functionally impaired with non-small cell lung cancer. The program included symptom-limited exercise and muscle electric stimulation; after that intervention the patients improved their pulmonary function and 6MWT and were able to undergo lung resection.

The length of preoperative PR for lung cancer resection is controversial. Three studies ${ }^{11,17,18}$ reported improvement in postoperative outcomes with short interventions. On the other hand, only a few studies have suggested the benefit of a preoperative PR program longer than 4 weeks, before lung cancer resection: (1) the study by Cesario ${ }^{13}$ mentioned before; (2) Bobbio et $\mathrm{al}^{19}$ in a prospective observational study observed the beneficial 
Table 3 Baseline and 1-month functional parameters for the 2 study groups

\begin{tabular}{|c|c|c|c|c|c|c|}
\hline \multirow[b]{2}{*}{ Parameter } & \multicolumn{2}{|c|}{$\begin{array}{c}P R \\
(n=12)\end{array}$} & \multirow[b]{2}{*}{$P^{\star}$} & \multicolumn{2}{|c|}{$\begin{array}{c}\text { CPT } \\
(n=12)\end{array}$} & \multirow[b]{2}{*}{$P^{*}$} \\
\hline & Baseline & $1 \mathrm{mo}$ & & Baseline & $1 \mathrm{mo}$ & \\
\hline $\mathrm{FEV}_{1}(\mathrm{~L})^{*}$ & $1.07 \pm .37$ & $1.26 \pm .61$ & .08 & $1.18 \pm .25$ & $1.31 \pm .35$ & .23 \\
\hline $\operatorname{FEV}_{1}(\%)^{*}$ & $48.1 \pm 13.9$ & $54.8 \pm 22.4$ & .27 & $51.7 \pm 9.8$ & $58.8 \pm 13$ & .08 \\
\hline $\mathrm{FVC}(\mathrm{L})^{\dagger}$ & $1.47(1.27-2.33)$ & $1.71(1.65-2.80)$ & .02 & $2.03(1.51-2.3)$ & $2.13(1.50-2.4)$ & .37 \\
\hline FVC $(\%)^{\dagger}$ & $62.5(49-71)$ & $76(65-79.7)$ & .01 & $62.5(56-92)$ & $71(63.2-89)$ & .36 \\
\hline $\operatorname{MIP}\left(\mathrm{cmH}_{2} \mathrm{O}\right)^{*}$ & $90 \pm 45.9$ & $117.5 \pm 36.5$ & .00 & $46.6 \pm 26.6$ & $67.6 \pm 39.9$ & .05 \\
\hline $\operatorname{MEP}\left(\mathrm{cmH}_{2} \mathrm{O}\right)^{*}$ & $79.7 \pm 17.1$ & $92.9 \pm 21.4$ & .01 & $52.7 \pm 24.5$ & $59.7 \pm 23.8$ & .13 \\
\hline 6MWT $(\mathrm{m})^{*}$ & $425.5 \pm 85.3$ & $475 \pm 86.5$ & .00 & $339.6 \pm 107$ & $335 \pm 107$ & .75 \\
\hline $\mathrm{P}_{2}(\mathrm{mmHg})^{*}$ & $79.6 \pm 8.8$ & $81.4 \pm 13.2$ & .56 & $75.6 \pm 5.8$ & $76.6 \pm 6.6$ & .48 \\
\hline $\mathrm{PcO}_{2}(\mathrm{mmHg})^{*}$ & $42.9 \pm 3.5$ & $42 \pm 3.4$ & .21 & $41.4 \pm 3.8$ & $41.8 \pm 3$ & .67 \\
\hline Sat $0_{2}(\%)^{*}$ & $95.5 \pm 1.5$ & $95.5 \pm 2.0$ & .87 & $94.7 \pm 1.2$ & $95.1 \pm 0.7$ & .43 \\
\hline
\end{tabular}

NOTE. Values are mean \pm SD or median (25th-75th percentiles).

Abbreviations: $\mathrm{FEV}_{1}$, forced expiratory volume in the first second; $\mathrm{FVC}$, forced vital capacity; $\mathrm{P}_{\mathrm{CO}_{2}}$, carbon dioxide partial pressure; $\mathrm{P}_{2}$, oxygen partial pressure; Sat $\mathrm{O}_{2}$, peripheral oxygen saturation.

* Paired $t$ test.

$\dagger$ Wilcoxon test.

effect of a 4-week preoperative PR program on exercise performance of 12 patients with COPD who were candidates for lung cancer resection; (3) Jones et $\mathrm{al}^{20}$ reported that preoperative exercise training could improve cardiorespiratory fitness of 18 patients undergoing pulmonary resection; and (4) Spruit et $\mathrm{al}^{21}$ reported a pilot study about the improvement of exercise capacity after an inpatient PR program during 8 weeks in 10 patients with lung cancer. In the present study, functional parameters measured before and after 4 weeks of preoperative PR demonstrated an improvement.

There is a major concern about the delay of curative surgery with the period of 4 weeks of PR before lung cancer resection. In our center, there is eagerness to proceed with surgery, so the 4 weeks we chose and the usual period of workup did not change the time course.

The previously cited studies in the literature are all nonrandomized studies with small sample sizes, and none of them evaluated the incidence of PPCs.

Table 4 Postoperative outcomes after 4 weeks of PR vs CPT

\begin{tabular}{|c|c|c|c|}
\hline Parameter & $\begin{array}{l}\text { CPT } \\
(n=9)\end{array}$ & $\begin{array}{l}P R \\
(n=12)\end{array}$ & $P$ \\
\hline Days in hospital ${ }^{*}$ & $12.2 \pm 3.6$ & $7.8 \pm 4.8$ & .04 \\
\hline ICU stay $(\mathrm{d})^{\dagger}$ & $2(2-4.5)$ & $2(2-3)$ & .20 \\
\hline Days with chest tubes* & $7.4 \pm 2.6$ & $4.5 \pm 2.9$ & .03 \\
\hline Patients with PPCs ${ }^{\ddagger}$ & $7(77)$ & $2(16.7)$ & .01 \\
\hline Pneumonia ${ }^{\ddagger}$ & $2(22.2)$ & $0(0)$ & .17 \\
\hline Ventilation $>48 \mathrm{~h}^{\ddagger}$ & $3(33.3)$ & $1(8.3)$ & .20 \\
\hline Bronchopleural fistula ${ }^{\ddagger}$ & $7(77.8)$ & $2(16.7)$ & .009 \\
\hline Atelectasis $^{\ddagger}$ & $3(33.3)$ & $0(0)$ & .06 \\
\hline Bronchospasm $^{\ddagger}$ & $6(66)$ & $0(0)$ & .002 \\
\hline
\end{tabular}

NOTE. Values are mean $\pm S D$, median (25th-75th percentiles), or $n(\%)$.

Abbreviation: ICU, intensive care unit.

* Student $t$ test.

† Mann-Whitney $U$ test.

¥ Fisher exact test.
In the present randomized study, a 4-week period of preoperative PR decreased the postoperative respiratory morbidity and was associated with a shorter length of hospital stay. Only 1 previous randomized study ${ }^{14}$ has been published showing the benefits of a shorter preoperative PR program before lung cancer resection in patients with poor lung function. In that study, Benzo et $\mathrm{al}^{14}$ showed that in patients with COPD who are candidates for lung cancer resection, a 10-session preoperative PR program significantly decreased the time of chest tube drainage and lowered the incidence of patients requiring chest tubes for a prolonged period. The authors also conducted another trial of a 4-week preoperative PR intervention, with poor results. Most of the patients or providers did not agree to delay the curative surgery for 4 weeks.

One of the postoperative outcomes of the present study was that in the PR group, few patients developed bronchopleural fistulas, and the number of days patients required a chest tube was decreased, the same outcomes observed by Benzo. ${ }^{14}$ The mechanism of the decrease in our study is unclear.

Another interesting finding of this study was that the PR group showed a significant improvement of the respiratory pressures and walking abilities after 1 month. We could attribute these benefits to the rehabilitation with routine use of muscle training. This result is in line with the study results of Hulzebos et al, ${ }^{17}$ who showed that IMT before thoracic surgery may improve preoperative MIP in patients undergoing coronary artery bypass graft surgery. The impact of preoperative IMT on the outcomes of thoracic surgery has been previously addressed. ${ }^{18,22,23}$

\section{Study limitations}

The very important limitations of this study are the small sample size and the loss of patients, which raise concerns about the generalizability of the study. We attempted to control for the loss of patients by using intent-to-treat analysis. The uneven randomization is also an issue. Although the power of the analysis was not calculated, some of the main variables in both phase 1 and phase 2 of the study achieved statistical significance in the comparisons between groups (PR vs CPT). 


\section{Conclusions}

To date and to our knowledge, this is the first randomized study showing the benefit of a 4-week PR program, administered to patients undergoing lung cancer resection, on preoperative functional capacity and postoperative morbidity. We consider this to be an important presurgical intervention that improves the conditioning status of the patients and appears to be effective at reducing morbidity in the postoperative period. Further trials, particularly the design of large confirmatory studies, are necessary to corroborate these findings.

\section{Suppliers}

a. HealthScan Products Inc, 908 Pompton Ave, Cedar Grove, NJ 07009.

b. NCS Indústria e Comércio Ltda, Rua Aeroporto 192, Chácaras Marco, Barueri-SP, 06419-260, Brazil.

c. IBM North America, 590 Madison Ave, New York, NY 10022.

\section{Keywords}

Lung cancer; Postoperative complications; Rehabilitation; Thoracic surgery

\section{Corresponding author}

Eanes D. Pereira, PhD, Rua Barbara de Alencar 1401, 60140000, Fortaleza, Ceará, Brazil. E-mail address: eanes@fortalnet.com.br.

\section{References}

1. Sherwood JT, Brock MV. Lung cancer: new surgical approaches. Respirology 2007;12:326-32.

2. Win T, Sharples L, Groves AM, et al. Predicting survival in potentially curable lung cancer patients. Lung 2008;86:97-102.

3. Damhuis RAM, Schutte PR. Resection rates and postoperative mortality in 7,899 patients with lung cancer. Eur Respir J 1996;9:7-10.

4. Little AG, Rusch VW, Bonner JA, et al. Patterns of surgical care of lung cancer patients. Ann Thorac Surg 2005;80:2051-6.

5. Benzo R, Kelley GA, Recchi L, et al. Complications of lung resection and exercise capacity: a meta-analysis. Respir Med 2007;101:1790-7.

6. Bartels $\mathrm{M}$, Kim $\mathrm{H}$, Whiteson $\mathrm{J}$, et al. Pulmonary rehabilitation in patients undergoing lung-volume reduction surgery. Arch Phys Med Rehabil 2006;87:84-8.
7. Takaoka ST. The value of preoperative pulmonary rehabilitation. Thorac Surg Clin 2005;15:203-11.

8. Celli BR. Chronic respiratory failure after lung resection: the role of pulmonary rehabilitation. Thorac Surg Clin 2004;14:417-28.

9. Wilson DJ. Pulmonary rehabilitation exercise program for high-risk thoracic surgical patients. Chest Surg Clin N Am 1997;7:697-706.

10. Chumillas S, Ponce JL, Delgado F, Viciano V, Mateu M. Prevention of postoperative pulmonary complications through respiratory rehabilitation: a controlled clinical study. Arch Phys Med Rehabil 1998; 79:5-9.

11. Sekine Y, Chiyo M, Iwata T, et al. Perioperative rehabilitation and physiotherapy for lung cancer patients with chronic obstructive pulmonary disease. Jpn J Thorac Cardiovasc Surg 2005;53:237-43.

12. Weiner $\mathrm{P}$, Man A, Weiner M, et al. The effect of incentive spirometry and inspiratory muscle training on pulmonary function after lung resection. J Thorac Cardiovasc Surg 1997;113:552-7.

13. Cesario A, Ferri L, Galetta D, et al. Pre-operative pulmonary rehabilitation and surgery for lung cancer. Lung Cancer 2007;57:118-9.

14. Benzo R, Wigle D, Novotny P, et al. Preoperative pulmonary rehabilitation before lung cancer resection: results from 2 randomized studies.

15. Roisin RR, Anzueto A, Bourbeau J, et al. GOLD-pocket guide to COPD diagnosis, management and prevention. A guide for health care professionals (updated 2009). Available at: http://www.goldcopd.org. Accessed April 20, 2010.

16. Shannon VR. Role of pulmonary rehabilitation in the management of patients with lung cancer. Curr Opin Pulm Med 2010;16:334-9.

17. Hulzebos EH, Helders PJ, Favie NJ, et al. Preoperative intensive inspiratory muscle training to prevent postoperative pulmonary complications in high-risk patients undergoing CABG surgery: a randomized clinical trial. JAMA 2006;296:1851-7.

18. Yánez-Brage I, Pita-Fernández S, Juffé-Stein A, et al. Respiratory physiotherapy and incidence of pulmonary complications in off-pump coronary artery bypass graft surgery: an observational follow-up study. BMC Pulm Med 2009;9:36-7.

19. Bobbio A, Chetta A, Ampollini L, et al. Preoperative pulmonary rehabilitation in patients undergoing lung resection for non-small cell lung cancer. Eur J Cardiothorac Surg 2008;33:95-8.

20. Jones L, Peddle C, Eves N, et al. Effects of presurgical exercise training on cardiorespiratory fitness among patients undergoing thoracic surgery for malignant lung lesions. Cancer 2007;110: 590-8.

21. Spruit MA, Janssen PP, Willemsen SCP, et al. Exercise capacity before and after an 8-week multidisciplinary inpatient rehabilitation program in lung cancer patients: a pilot study. Lung Cancer 2006;52:257-60.

22. Stein R, Maia CP, Silveira AD, et al. Inspiratory muscle strength as a determinant of functional capacity early after coronary artery bypass graft surgery. Arch Phys Med Rehabil 2009;90:1685-91.

23. Nomori H, Kobayashi R, Fuyuno G, Morinaga S, Yashima H. Preoperative respiratory muscle training: assessment in thoracic surgery patients with special reference to postoperative pulmonary complications. Chest 1994;105:1782-8. 